A R T TÍ C C U L O D D E I $N$ VES T I G A C I Ó $N$ $\begin{array}{llllllllllllllllll}C & I & E & N & T & I & F & I & C & A & Y\end{array}$

TEE C N O L L Ó G I C A

\title{
REALIDADES DE MUJERES QUE PROMUEVEN ORGANIZACIÓN Y PARTICIPACIÓN DESDE SUS TERRITORIOS, EN UNA SOCIEDAD QUE INTENTA TERMINAR CON EL CONFLICTO ARMADO1
}

\author{
REALITIES OF WOMEN WHO PROMOTE ORGANIZATION AND \\ PARTICIPATION FROM THEIR TERRITORIES, IN A SOCIETY THAT \\ TRIES TO END UP THE ARMED CONFLICT
}

Por: Martha Elena Saboya Ramírez*

Trabajadora social de

la Universidad Nacio-

nal de Colombia, ma-

gister en Política Social

de la Universidad Ex-

ternado de Colombia.

Actualmente es docente

del programa de Traba-

jo Social de la Funda-

ción Universitaria Cer-

vantina San Agustín.

E-mail: masara16@

hotmail.com; martha.

saboya@unicervanti-

na.edu.co

1 Investigación propuesta por el Programa de Trabajo Social avalada por el Comité de Investigaciones y financiada por la Fundación Universitaria Cervantina San Agus-

tín. UC-PROYIN-01. Bogotá 2016

\begin{abstract}
RESUMEN
Hoy en día en Colombia, mujeres residentes en María la Baja, municipio del departamento de Bolívar, persisten en sus procesos organizativos para atender al desarrollo de objetivos reivindicatorios con ocasión de las consecuencias y secuelas generadas por el conflicto armado. Sus interacciones, gestiones y movilizaciones ante el Estado, centran su atención en la búsqueda de la restauración de sus derechos y los de sus familias debido al desplazamiento. Pretenden lograr el retorno a sus tierras, contar con vivienda segura y servicios públicos, trabajar de manera digna y honrada, como siempre fue y ha sido su aspiración. En estos procesos identifican y vivencias nuevas formas de entender y comprender los fenómenos sociales, en consecuencia direccionan sus apuestas sociales e introducen cambios en sus entornos familiares y en su diario vivir.
\end{abstract}

Palabras clave: mujer, violencias, estado, derechos, participación.

\begin{abstract}
Nowadays in Colombia, women living in María la Baja, a municipality in the department of Bolívar, persist in their organizational processes to attend to the development of claiming objectives in view of the consequences generated by the armed conflict. Their interactions, efforts and mobilizations to claim the State, focus their attention on the search for the restoration of their rights and those of their families due to displacement. They aim to achieve the return to their lands, to have safe housing and public services, to work in a dignified and honest manner, as it always was and has been their aspiration. In these processes, they identify and experience new ways of understanding the social phenomena, thus directing their social bets and introducing changes in their family environments and daily life.
\end{abstract}

Keywords: women, violence, state, rights, participation. 
"Aprendimos a salir de la condición de pobres víctimas a las cuales todo se lo tienen que dar, por los cuales se debe sentir lastima, a pasar a ser sujetos de derechos". Testimonio de Juana.

\section{Introducción}

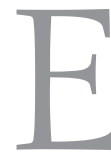

l Programa de Trabajo Social formuló en el segundo semestre de 2015, un proyecto de investigación, denominado: "Procesos de redefinición del rol social femenino a la luz de la ética de género", el cual fue aprobado a finales de ese año y ejecutado en 2016.

El estudio se realizó con nueve organizaciones de mujeres ubicadas en diferentes regiones del país. En el presente año se publicará el libro que dará cuenta de la experiencia investigativa en su conjunto.

En este artículo presento la experiencia investigativa con una de las organizaciones asentada en el departamentos de Bolívar, específicamente en el municipio de María la Baja, territorio de enorme riqueza natural, pero signado por realidades humanas de alta confrontación y sufrimiento.

Inicialmente se expondrá el carácter de la investigación, la metodología para el abordaje de las realidades, posteriormente se relatarán los contextos y las apuestas de la organización de mujeres, para terminar con reflexiones y análisis en consideraciones finales.

La investigación, partió de la siguiente pregunta:

¿Las mujeres evidencian procesos de transformación y cambio en su mundo privado y en la visión de la sociedad y de lo público, cuando toman la decisión de participar en organizaciones gestadas y direccionadas por ellas?

Identificar si existen o no cambios en la vida de las mujeres, en sus espacios e interacciones familiares y cambios en la comprensión, valoración de lo colectivo, de lo social, cuando mancomunadamente con otras mujeres deciden constituir organizaciones que cumplan objetivos diversos ante condiciones de vulnerabilidad, pobreza y exclusión, constituyó el meollo o cuestión central a investigar.

Pero ipor qué esta pregunta? Porque inquieta indagar sobre el sentido y significado que las mujeres dan a sus acciones; porque se desea conocer si 
efectivamente las mujeres integradas a organizaciones sociales se apropian de nuevas formas de apreciar y comprender sus complejas problemáticas y necesidades; sencillamente porque interesa conocer si los objetivos y metas de sus organizaciones son puestas en escena con la intención de reivindicar derechos que apunten al logro de sus aspiraciones colectivas y de igual manera a transformar su forma de actuar en la vida familiar o si persisten otro tipo de valoraciones por las cuales se vinculan a ellas. Igualmente la pregunta pretende inquirir sobre las formas y maneras como visibilizan sus realidades familiares y su cotidianidad cuando deciden participar en organizaciones promovidas por ellas.

\section{Metodología}

l enfoque de la investigación es cualitativa, dirige su atención a lograr aproximaciones a realidades concretas y a profundizar en el significado que las mujeres le otorgan a sus experiencias y vivencias. Las categorías establecidas para centrar y articular la investigación fueron las siguientes: rol sociocultural, organización, participación, empoderamiento y equidad de género.

\section{Roles socioculturales}

En el ámbito más general del trabajo humano y de los desempeños más representativos de cada sexo, históricamente se encuentra la asignación de unos roles direccionados a las mujeres y otros a los hombres, esto ha fundamentado estructuras que jerarquizan, que asignan ordenamientos y pautas para los desempeños de unas y de otros. Estos roles configuran prácticas y a su vez se convierten en principios valorativos y evaluativos de lo esperado en la sociedad para ellos y para ellas. "Las representaciones dicotómicas de los géneros, imponen tanto a mujeres como a hombres, limitaciones en su crecimiento personal, diseñan subjetividades contrapuestas, excluyentes que atraviesan la propia vida tanto en sus aristas privadas como públicas. Esto promueve una estereotipia que desarticula cualquier empeño por establecer relaciones interpersonales y el desarrollo de una cultura más humana" (Fernández 2000). Estas valorizaciones diferenciales, profundamente ancladas en la cultura han desdibujado el papel de la mujer, reducido y limitado su actuar, todo lo cual se traduce en una manifiesta desigualdad entre ambos sexos en la vida social y económica.

El androcentrismo persiste, ante confrontaciones y debates públicos y privados, se reinstala como referente en las interacciones humanas y se 
reproduce de diferentes maneras en espacios, tiempos y condiciones variables. Indudablemente esta condición adquiere múltiples matices dependiendo de factores asociados a logros educativo-formativos alcanzados por las mujeres, al mayor o menor grado de afrontamiento mediado por la toma de decisiones ante hechos atentatorios contra su dignidad y al mayor o menor grado de asimilación y arraigo de preceptos y creencias ligadas a la sumisión, paciencia y conformismo. Transformaciones se han venido construyendo, pero existen largos caminos por recorrer y obstáculos por sortear.

Identificar cómo estas desigualdades permean la vida entre hombres y mujeres, constituyó uno de los temas que se intentó mirar en los relatos suministrados por las mujeres que participaron en la investigación.

\section{Organización de mujeres}

Se centró el interés en las organizaciones de base comunitaria en su calidad de "autónomas o insertas dentro de entidades más amplias, que se conforman con el fin de enfrentar colectivamente necesidades familiares o comunitarias o que suplen los servicios públicos y sociales que el Estado deja de prestar" (Ramírez 1989). Organizaciones que no siempre nacen con estructuras jerarquizadas de dirección, pero que dependiendo de sus avances, despliegue de actividades y consolidación tienden a buscar una estructura formal para atender diversas funciones y proyectar su trabajo.

Esas formas de organización en los espacios comunitarios y su gestión y presión ante el Estado, la institucionalidad pública y los entes privados, han permitido crear vínculos y servicios entre las mujeres que las convocan y mecanismos que han servido para favorecer la comunicación, el apoyo ante situaciones críticas, eventos de calamidad, sobrevivencia, autoayuda y para desarrollar iniciativas productivas y culturales.

Destacar que a lo largo de la historia del país, las mujeres se han organizado para enfrentar y confrontar al Estado en razón de la defensa de la nación, del trabajo y de las condiciones sociales y culturales que la discriminan. "En 1928 aparecieron mujeres participando colectivamente del movimiento de las bananeras....en el mismo año en Bogotá en contra de la corrupción en la administración...en contra de la incapacidad civil y de su nula autonomía económica... la participación de destacadas mujeres en la huelga femenina de Fabricato, en la adopción de una legislación obrera para crear cajas y fondos para la maternidad" (Villareal 2009). 
Más adelante, resultan destacables los movimientos que trabajaron por el reconocimiento de la ciudadanía, por el ejercicio del sufragio y por las circunstancias organizativas presentes a partir de los años cincuenta del siglo pasado. Es evidente que la dinámica económica y social del país siempre ha estado como telón de fondo en las tareas organizativas de las mujeres; los procesos de industrialización, urbanización y modernización, conllevaron a la par a sortear condiciones críticas en el orden de la vida familiar, social, cultural frente a lo cual las mujeres han cumplido un papel activo, desde sus realidades concretas y desde sus territorios, para identificar alternativas de manejo ante las nuevas necesidades y problemáticas surgidas.

La presencia de las mujeres en las organizaciones sindicales inicio desde la segunda década del siglo XX. Según el censo sindical de 1991 del Ministerio de Trabajo, se destaca el avance de las mujeres en las organizaciones sindicales desde un 28\% en 1964, hasta un 40\% entre los años 80 y 90; procesos asociativos que a partir de esta época tienden a descender en la medida que se introducen reformas al Código Sustantivo del Trabajo y avanza la legislación relativa a la flexibilización laboral.

A lo largo de la historia del país, han hecho presencia diversas formas organizativas, unas guiadas por propósitos inmediatos tendientes a intervenir o resolver problemas inminentes y otras han estado guiadas por iniciativas de largo aliento; "los movimientos de mujeres son heterogéneos tanto en lo que hace a su ideología y a su estructura organizativa como en cuanto a las formas de movilización, de lucha y de acción política" (Ramírez 1989). Sus expectativas transitan entre la defensa de derechos ante vulneraciones o por el acceso a escenarios para poner en conocimiento y evidencia sus intereses y expectativas de desarrollo.

\section{Participación de las mujeres}

En el sentido más amplio y acorde a lo estipulado en el año 1991 en la Constitución Política del país, todo ciudadano tiene derecho a participar en la conformación, ejercicio y control del poder político. Esta concepción estratégica es valedera como principio guía en las democracias, pero solo se construye y dinamiza en ejercicios concretos en los cuales la ciudadanía en general y las mujeres, para nuestro tema en particular, tengan la posibilidad de acceder a diferentes escenarios donde la reflexión, el debate, el respeto por su voz sea el insumo para el establecimiento de acuerdos y acciones. 
La participación efectiva de las mujeres en las organizaciones donde hacen presencia, puede identificarse por la expresión de su pensamientos y sentimientos, por las posturas propositivas y proactivas, por los silencios que se instalan cuando tienen el uso de la palabra y son escuchadas; éstas condiciones se facilitan, cuando las dirigentes de las organizaciones otorgan relevancia y significación a este derecho para todas y cada una de sus asociadas.

Participar tiene connotaciones múltiples, es un fin esencial, no es meramente una posibilidad ciudadana, es un potencial instalado en la esencia del ser humano y por tanto se considera como "valor de la convivencia, la democracia y la acción social" (Vargas 1994, 40); sin descontar lo que supone como involucramiento, responsabilidad y compromiso.

La participación de la mujer ha estado limitada por múltiples barreras, las cuales no se pueden desconocer. Según Barreto estos obstáculos están asociados a factores de carácter cultural, expresados en: "la invisibilización de su presencia en los espacios públicos; la dicotomización, o papel socialmente asignado y que "naturaliza" su razón de ser al mundo de lo privado, de lo doméstico, mientras que avala y legitima la vivencia de lo público para el hombre; la concepción complementaria, según la cual su papel en la sociedad sólo procede a partir de la relación establecida con el hombre; la presunción maternizante que identifica esencialmente mujer con maternidad y finalmente la postura culpabilizante que señala a la mujer como "abandonadora" del hogar y los hijos, cuando decide participar y ampliar el mundo de sus realizaciones". (Barreto 1997).

Es de esperar, que cuando las mujeres logran superar estos óbices a partir de nuevas construcciones mentales y de nuevas decisiones adoptadas, su participación se hace vital para lograr el fortalecimiento de su vida personal, familiar y social y de las organizaciones donde actúa; en estas últimas se materializa en la manifestación de su palabra y sus argumentos, lo que da paso en colectivo, al disenso, al consenso, toma de decisiones, actuación, movilización y gestión.

\section{Empoderamiento}

Remite a considerar la capacidad de las mujeres para asumirse como sujetos de derechos como ciudadanas, como personas dueñas de sus propias vidas, con la posibilidad de actuar solo a partir de la conciencia sobre sus ideales y sus búsquedas; es la adopción de una manera diferente de ver la vida, es el 
paso del estatismo que estanca a otra condición que dinamiza y promueve cambios en sus realidades.

Empoderar, habla de la capacidad de asumir desafíos y retos que conducen al desarrollo del potencial, de las habilidades y de las capacidades. Corresponde a una decisión deliberada que tiene por meta ampliar o acrecentar la autodeterminación y el autogobierno en los diferentes escenarios de su vida, contribuyendo, a su vez, a modificar las relaciones inequitativas.

El rasgo más sobresaliente del término empoderamiento es la palabra poder, la cual hace mención a "control sobre los bienes materiales, los recursos intelectuales y la ideología" (Srilatha 1997, 191). Enajenada su mente y su cuerpo por siglos, la mujer ha decidido reencontrarse para ejercer el gobierno de su ser, para pensar, sentir y actuar acorde a sus vivencias y realidades; para tomar el mando y la dirección de su existencia. La evidencia histórica es clara respecto a la condición de desigualdad de la mujer respecto al hombre, expresada de múltiples formas y en la convivencia privada y pública. El empoderamiento, en consecuencia, surge como la estrategia necesaria a adoptar para trabajar con miras a que los intercambios se den en igualdad de condiciones, en este sentido subyace una dimensión emancipadora.

Mujeres que han venido asumiendo esta nueva mirada sobre sus vidas, potencian sus capacidades y adelantan de manera autónoma sus proyectos para posicionarse en los territorios y en los espacios donde residen y donde aspiran a cumplir un papel destacado; allí hacen valer su renovada condición asumiendo compromisos, deberes y corresponsabilidades de manera voluntaria, autónoma y por el solo interés de aportar en los procesos de transformación social.

Pero esa capacidad para asumirse por fuera del hogar igualmente se vuelca en su mundo privado en el ámbito familiar; transforma dependencias, apegos e imaginarios que validan la condición de subalterna; además de ser una decisión personal se constituye en reto para comprometerse con el abanico de posibilidades que se abre ante ella, cuando decide dar pasos en pro de su vida, de sus sueños y aspiraciones.

\section{Equidad de género}

Hace relación directa con los valores de justicia social, en su dimensión colectiva y moral. La equidad de género se realiza en la aceptación del igual valor de 
las personas y en la obligatoriedad del Estado y de la sociedad para garantizar a todas y todos acorde a sus necesidades, habilidades y potencialidades, el total desarrollo de su condición humana. Implica la resonancia en simultáneo entre la ley, las valoraciones sociales y las valoraciones individuales, para que tanto hombres como mujeres se reconozcan y cuenten con las mismas oportunidades para su desarrollo, en fin para superar todo el constructo que "desde las diferencias de la anatomía y las funciones biológicas específicas de cada sexo, fueron construyendo especificidades culturales y sociales que se naturalizaron" (Gómez 2005,36).

Entender en su plena dimensión la equidad de género, amerita contar con un lente panorámico el cual permita trascender la importante acción legislativa y reglamentaria para poner en manos del conjunto de la sociedad el esfuerzo por trabajar mancomunadamente para la superación de patrones culturales anclados en lo profundo de las individualidades y que reproducen ideas de superioridad en unos e inferioridad en otros.

La equidad de género se construye en escenarios legislativos y en los diferentes espacios sociales por donde circulan a diario hombres y mujeres, tales como el hogar, el colegio, el trabajo, el barrio, el parque, la universidad, el encuentro deportivo; en todos y cada uno de estos escenarios se manifiestan posturas $y$ actitudes que dignifican o violentan el intercambio humano.

Cambiar ideas y modelos convencionales de género sustentados en la diada dominación-subordinación, en los estereotipos de masculinidades superiores y feminidades inferiores es tarea insoslayable. Es la aceptación de la plena condición humana, donde todas las personas son iguales, únicas y diversas, es decir, iguales en la diferencia.

Una renovada valoración social de la mujer en la mente de todos los seres humanos, en conjugación con normas legales y reglamentarias que fomenten medidas de acción positiva, tendrá efecto favorable en la construcción de nuevas ciudadanías respetuosas y proactivas de cara a la equidad.

Una vez establecidas las categorías, surgió la pregunta sobre los lugares, los territorios donde se adelantaría la investigación. El criterio para tomar esta decisión lo aportó el estudio que la oficina de la CEPAL en Colombia propuso al gobierno colombiano para clasificar los departamentos y mediante el cual los organiza a partir de la identificación de cinco indicadores, que permiten 
verificar sus niveles de desarrollo. Los indicadores son: fortaleza de la economía, avances tecnológicos, capital humano, infraestructura, instituciones políticas e instituciones administrativas, estas variables, según los expertos, moldean los progresos económicos y sociales de las regiones.

Las fortalezas y debilidades de cada uno de los indicadores y la tendencia en el largo y corto plazo son los criterios para clasificar los departamentos dentro del marco de competitividad, es decir de "la capacidad para tener una economía y una sociedad, cuyo desarrollo resulta atractivo en términos de la competencia económica como de las demás competencias que tiene un territorio para lograr un desempeño moderno, con fortalezas, equilibrios, integralidad, diversidad y resiliencia". (Ramírez y De Aguas 2015, 1).

A partir de la articulación de estos indicadores, el estudio de la CEPAL construyó perfiles o líneas características que permiten la clasificación diferencial de los departamentos del país; este hecho tomado en consideración, contribuyó a aportar elementos para la definición dentro del abanico de posibilidades. En definitiva se eligió un departamento por cada uno de los siguientes perfiles:

- Extra líder. Cundinamarca, representando la región central del país. La tendencia de cuatro indicadores es creciente y en el largo y corto plazo evidencian estabilidad.

- Líder. Valle del Cauca, representando la región Pacífica. La tendencia de tres indicadores es alto y en el largo y corto plazo pueden presentar estancamiento.

- Medio alto. Bolívar, representando la región Atlántica. La tendencia de cuatro indicadores es mediana con alguna tendencia a lo alto y en el largo y corto plazo pueden presentar características emergentes.

- Medio bajo. Cesar, representando la región Atlántica. La tendencia de tres indicadores es mediana, una con tendencia a lo alto y dos con tendencia a lo bajo y en el largo y corto plazo pueden presentar características emergentes. Igualmente Nariño, representando la región Pacífica. La tendencia de tres indicadores es mediana, una con tendencia a lo alto y dos con tendencia a lo bajo y en el largo y corto plazo pueden presentar características emergentes.

Teniendo en claro los departamentos, se procedió a la búsqueda de las organizaciones de mujeres, tarea que demandó acciones y tiempos importantes; una vez se tuvo respuestas favorables por parte de las representantes legales 
o líderes de las mismas, se identificó el municipio sede de la organización. La disposición de las organizaciones de mujeres que dieron el sí, en aceptación de su voluntad para aportar sus conocimientos y trayectoria al proceso investigativo, pasó por los necesarios filtros solicitados por las organizaciones: presentación de la universidad, del programa académico, de los objetivos de la investigación, identificación de las docentes. Las representantes legales y líderes realizaron consulta con sus juntas directivas y equipos de trabajo, a fin de establecer su disponibilidad frente al estudio.

Importante anotar que las organizaciones que respondieron tenían por objetivo atender a situaciones o secuelas producto del conflicto armado hecho que llamo la atención, pues la cruenta violencia que por décadas ha vivido el país, logra transversalizar los procesos sociales de las comunidades; en muchos de los casos su origen y objetivos han estado asociados a enfrentar, mitigar o atender los "productos" o "subproductos" generados por esta dolorosa y perturbadora realidad del país.

La recolección de la información fue obtenida de entrevistas estructuradas, semiestructuradas y grupos focales, cada una de estas técnicas con sus pertinentes guías de trabajo construidas a partir de las categorías establecidas. Las entrevistas y trabajos grupales se desarrollaron acorde a los tiempos establecidos con las diferentes organizaciones, con acogida total de las personas de las organizaciones y sin contratiempos insalvables. Se recopilaron materiales adicionales: grabaciones de audio, video, publicaciones elaboradas por las organizaciones y carteleras trabajadas en desarrollo de los grupos focales, todo lo cual ha contribuido al logro de las sistematizaciones y análisis respectivos.

Los relatos de las mujeres fluyeron a partir de preguntas y de respuestas en donde expresaron sus formas de pensar y los significados que atribuyen a sus realidades en torno a los temas puestos en consideración. El trabajo investigativo, a su vez, incorporó la atención al contexto, a los antecedentes históricos, a los conflictos y las contradicciones presentes en los diversos escenarios sociales.

Se realizó en los ambientes familiares de las mujeres, en sus hogares, dado que las organizaciones no cuentan con sedes; estos lugares fueron propicios para la comunicación y allí se configuraron las condiciones necesarias, que de acuerdo con Hoyos, favorecen "el reconocimiento del otro como diferente, es 
decir, como interlocutor válido, pues sólo quien reconoce esto sigue interesado en la comunicación con los demás, dado que considera que puede aprender de ellos. Este es el punto de partida de toda ética: el reconocimiento del otro como diferente". (Ayala 2007).

En las respuestas obtenidas quedan plasmadas sus creencias, valores, ideas, pensamientos y emociones, que dan forma a la comprensión de su pasado, presente y proyección de futuro; la cercanía a los mundos cotidianos de las mujeres y a sus tareas en la organización, contribuyeron al encuentro de respuestas a la pregunta inicial de la investigación.

Durante el proceso, correspondió al investigador, disponerse para asumir el pensamiento y la emocionalidad presente en la palabra, la carga afectiva articulada en el discurso, la pausa entre palabra y palabra, la entonación, los silencios y la expresión gestual. La observación participante fue otra herramienta que permitió el registro de vivencias presentes antes, en y posterior a las actividades centrales de recolección de la información.

Se desarrollaron por cada una de las organizaciones de mujeres, varias sesiones para la recolección de la información, las cuales se efectuaron por lo general en dos días: entrevista estructurada a la líder, que en el caso de las formales, correspondió a la representante legal y en el caso de las informales a la mujer destacada que aglutina y direcciona la agrupación de mujeres y que tiene reconocimiento; se desarrollaron entre tres o cuatro entrevistas semiestructuradas a participantes o asociadas y un grupo focal en el cual participaron de cuatro a ocho mujeres. De acuerdo a las realidades específicas de cada organización los tiempos se ampliaron o disminuyeron.

\section{Asociación para la Vida Digna y Solidaria: Mujeres tejiendo sueños y sabores de paz. Mampuján Nuevo. María la Baja.}

El contexto. Sería impensable iniciar el recuento sobre la investigación adelantada con esta organización, sin antes ampliar la mirada para reseñar la condición del país y la de su entorno próximo.

La violencia que ha padecido Colombia durante muchas décadas ha ocasionado ingentes pérdidas en vidas humanas, desolación, temor, miseria y décadas perdidas en posibilidades de desarrollo a todo nivel. Incluso pretender tener una aproximación al sinnúmero de muertes acaecidas resultaría una utopía. 
En el siglo pasado, historiadores colombianos que profundizadaron estos hechos, indicaban que la violencia se constituía en el más grave peligro que haya tenido la nacionalidad.

En referencia a la primera ola de la violencia (1949 a 1953) y a la segunda ola de la violencia (1954-1958), desatada entre los partidos políticos en su lucha por el poder, se afirmaba: "La nación carece de la noción exacta de lo que fue la violencia: ni la ha sopesado en toda su brutalidad aberrante, ni tiene indicios de su efecto disolvente sobre las estructuras...ni de su incidencia en la dinámica social...ni de las tensiones que creó, ni de la crisis moral que presupone" (Guzmán 1962, 14-292). De acuerdo al valeroso y profundo estudio desarrollado por Fals Borda, Umaña Luna y Guzmán, el gran total de personas muertas en las dos olas de violencia reseñadas estaría entre 180.000 y 200.000.

Pero el país evidenció la continuación del conflicto armado, nuevos ingredientes hicieron presencia en el escenario nacional: narcotráfico, guerrillas de variada orientación ideológica, paramilitarismo e innumerables acciones de las fuerzas militares del Estado, estas últimas, en ocasiones, en asocio con grupos de autodefensa; todas estas facciones alentaron la violencia a lo largo de las cinco décadas siguientes. El conflicto armado colombiano, además ha provocado inmensurables pérdidas materiales, desolación, abandono de tierras, reconfiguración de los territorios y de sus usos, asesinatos selectivos, desapariciones forzadas, degradación moral, y abandono de la esperanza por el encuentro de un mejor vivir. Estrictamente en términos de vidas humanas, el GMH, afirma que: "entre 1958 y 2012, murieron 40.787 combatientes; al compendiar estas cifras, es posible afirmar que en este periodo el conflicto armado colombiano ha provocado aproximadamente 220.000 muertos. De estas muertes el 81,5\% corresponde a civiles y el 18,5\% a combatientes; es decir que aproximadamente ocho de cada diez muertos han sido civiles, y por lo tanto, son ellos — personas no combatientes, según el Derecho Internacional Humanitario - los más afectados por la violencia" (Centro Nacional de Memoria Histórica 2013, 32).

El conflicto armado no ha dado tregua. Varias generaciones han nacido, crecido e incluso muerto sufriendo los desmanes a cuenta de este flagelo sobre todo en campos y ciudades intermedias; entre tanto la gran urbe, las grandes ciudades soslayan en actitud indiferente estas realidades, a pesar de que en la década del 90 Bogotá, Medellín y Cali experimentaron situaciones fuertes en el tema de seguridad. 
El departamento de Bolívar, desde luego no ha sido ajeno a estas realidades. Periodo altamente crítico, vivieron algunos territorios del país, como los Montes de María, "entre 1997-2007, sobresalieron tres actores armados ilegales, los paramilitares, las FARC y el ELN. Las guerrillas han hecho presencia en el departamento desde la década de 1970, mientras que las autodefensas desde la de 1980 y buscaron fortalecerse desde finales de la década de 1990". (Misión de observación Electoral-Corporación Nuevo Arco Iris 2008). Estos últimos ingresan por el sur del departamento y en contados años acceden al norte del departamento, provenientes de departamentos cercanos. Llevaron a cabo incursiones en contra de la población civil, para conseguir posesión, dominio y control territorial, mediante intimidación, amenaza y para dejar en claro a las comunidades que quienes apoyaran a los grupos guerrilleros serían convertidos en objetivo militar. El accionar de todos los grupos armados ilegales se recuerda con temor y tensión, pero sin lugar a dudas la ejecución de seis masacres a cargo del paramilitarismo y en las cuales se cometieron los crímenes más atroces que la mente humana pueda imaginar, permanece en el recuerdo de los sobrevivientes como hechos de sevicia sin límites en contra de la dignidad individual y colectiva.

Pero también aparecieron los desplazamientos, por múltiples razones: como consecuencia del conflicto, o por intereses ilegales sobre los territorios, como en el caso del narcotráfico y la minería ilícita o por presiones de inversionistas en tierras para el desarrollo de proyectos minero-energéticos y/o agroindustriales.

Sin embargo, es en esta misma época en donde a pesar de temores, miedos e incertidumbres, se reactivan y surgen formas asociativas que confrontan la muerte; surgen y se fortalecen colectivos y organizaciones que se movilizan por la justicia y contra la impunidad, con activa participación de movimientos indígenas, afro, campesinos y el surgimiento de organizaciones de mujeres.

La asociación. Lo antes mencionado fue observado en la organización de mujeres investigadas en María la Baja, la Asociación para la Vida Digna y Solidaria, su proceso asociativo data de los primeros años de la década del 2000; las líderes de esta organización y sus familias fueron víctimas por desplazamiento, es decir desarraigo de su territorio, del lugar donde nacieron y donde con el tiempo vieron crecer a sus hijos, arar la tierra, sembrar y recoger 
sus cosechas. Destierro que conllevó a perder el acceso a sus tierras y a su uso tradicional, fuente de la cual derivaban ingresos; se vieron impelidos a alterar el contacto con los cercanos, sus familiares y vecinos, es decir con las personas con las cuales habían construido en su entorno, un modo de ser y actuar; con los cuales compartían usos y costumbres, es decir unos patrones culturales de vida.

Allí en Mampuján, como en las tantas zonas del país donde ocurrieron desplazamientos, se modifica el paisaje. Tras la abrupta salida de sus habitantes, emergen condiciones nuevas: maleza, desolación, abandono por más de una década e intentos de reconstrucción mínima del pueblo sin garantía habitacional y de seguridad.

En otros casos de desplazamiento como lo advierten investigadores: "pequeñas fincas que eran cultivadas con variados productos agrícolas se han convertido, en extensas y uniformes extensiones de tierra cultivada con palma, como ocurrió en el Catatumbo o mutan a zonas despejadas para la explotación minera, como en el Pacífico" (Centro Nacional de Memoria Histórica 2015, 255). Las familias desplazadas difícilmente retornan y si lo hacen no hay garantía para que el regreso se de en condiciones dignas; si deciden quedarse en el nuevo lugar, el que las albergó, se ven enfrentadas a dificultades para lograr apoyo, reconocimiento y la integración requerida. El desalojo sistemático de campesinos y las circunstancias económicas y sociales de la población desplazada es la mayor crisis humanitaria que ha vivido el país a lo largo de su historia. "El desplazamiento interno constituye una de las mayores problemáticas que afronta el Estado. Este fenómeno alcanzó la suma de 6'044.200 personas desplazadas, como resultado de la lucha armada que ha persistido durante más de 50 años en el país, lo cual lo posiciona en el segundo Estado con mayor desplazamiento forzado en el mundo". (Centro de Monitoreo de Desplazamiento Interno del Consejo Noruego para Refugiados 2015).

La presente investigación, identificó que núcleos familiares han sido víctimas de múltiples formas de afectación; en muchos casos en calidad de sobrevivientes, sufren, enfrentan y llevan el peso de los daños provocados por la violencia. Marcas han quedado en sus cuerpos por agresiones físicas y afectaciones psicológicas, desamparo, dolor y sufrimiento por la expulsión. Duelos por el cambio radical de sus proyectos de vida exigido por violentos, por arrasadores. 
El municipio de María la Baja se encuentra cerca a Cartagena, es un territorio que tiene condiciones favorables para la habitabilidad, por la riqueza de sus tierras que la hacen aptas para los cultivos, por la abundancia de agua para el desarrollo de la agricultura y la ganadería. Se cultiva arroz, yuca, plátano, ñame, maíz y hay actividad de pesca. Este municipio se convirtió desde hace más de una década en el receptor de las familias desplazadas del corregimiento de Mampuján.

Tema que ha venido generando conflicto desde hace algunos años, en esta región, es el de la expansión de los cultivos agroindustriales, por cuanto ha puesto en cuestión el uso de la tierra que en el pasado reciente era de tradición campesina y ahora se usa en gran proporción para el monocultivo de la palma de aceite. La presión por vía legal o ilegal a pequeños propietarios ha generado problemas entre la población campesina, todo lo cual se suma al daño ambiental, producto del monocultivo en los cuerpos de aguas.

La Asociación para la Vida Digna y Solidaria es liderada por Juana Ruiz, mujer recia y firme en sus principios y objetivos, quien durante diecisiete años con la participación de otras mujeres, y el apoyo de sus esposos y compañeros, ha asumido tareas de defensa de las familias desplazadas, con miras a lograr el ansiado retorno.

Las mujeres de esta asociación asumieron el tejido como forma de "terapia", para resignificar hechos violentos acaecidos en marzo de 2.000, esto es, 17 años atrás y que conllevaron al desplazamiento de más de 245 familias, aproximadamente 620 personas, como bien lo relata en sus narrativas Juana Ruiz y otros lugareños. El objetivo del grupo paramilitar que realizó la incursión era masacrar a la comunidad, como lo habían hecho un mes antes con los pobladores de El Salado, pero recibieron cambio de instrucciones a última hora y entonces "el grupo armado ordenó a toda la comunidad abandonar el territorio y dirigirse al casco urbano del municipio de Marialabaja y resguardarse en la alcaldía" (Ruiz 2013, 1). Hoy en día, después de década y media, no existen condiciones dignas para el retorno.

Amenazados, salieron todos con lo poco que pudieron llevar en sus manos, espalda y en las mulas que algunos tenían; evacuaron su poblado antes del amanecer, dejaron atrás sus hogares, sus posesiones, su patrimonio y su forma de vida. Se ubicaron en el municipio de María la Baja en escuelas y otros albergues asignados por la alcaldía, después de unos años consiguieron 
un terreno a la entrada del mismo. Han trabajado arduamente para reconstruir sus vidas en Mampuján Nuevo y allí, la líder, en ardua tarea con otras mujeres y hombres constituyeron la asociación, para iniciar ante el Estado la defensa de los derechos vulnerados, para lograr el retorno y para mantenerse unidos y solidarios en la consecución de elementos materiales y alimentos para garantizar la supervivencia. Igualmente con gran tezón, sostuvieron y sostienen procesos tendientes a lograr el cumplimiento de las medidas de reparación integral a las víctimas de los hechos ocurridos en su natal Mampuján.

Ubicada la comunidad desplazada en la entrada del municipio de María la Baja, algunos han levantado pequeñas casa lotes, se han involucraron en el proyecto "Sembrando Paz", que ayuda a la comunidad a recuperarse del trauma de haber sido desplazados. Congregadas en actividades centradas en el manejo de la aguja e hilo y conocedoras de la técnica tela sobre tela "quilt", iniciaron bordados y mientras los realizaban hablaban de sus experiencias y sus sentimientos, de sus propias historias y las iban plasmando en telones. Mediante esta labor manual se iniciaron procesos de manejo del duelo, de recuperación de la memoria y sanación. Crearon el proyecto Mujeres tejiendo sueños y sabores de paz en 2004 y en este proceso han contado con el apoyo de congregaciones cristianas y otras personas y organizaciones que se unieron a su causa.

Pero su labor va más allá, manteniéndose unida la comunidad de familias desplazadas y ejerciendo acciones a partir de los recursos establecidos en la Constitución Nacional y de lo expresado en la Ley de Justicia y Paz (Ley 975 de 2005) han avanzado en la búsqueda de respuestas por parte del Estado en lo correspondiente a medidas de reparación; algunas familias han sido indemnizadas con montos económicos específicos y las que no, siguen adelantando procesos burocráticos para demostrar su condición de víctimas y poder recibir los dineros de reparación, los cuales, desde luego jamás lograrán indemnizar y compensar los daños y perjuicios. Han confrontado al Estado a fin de lograr el retorno en condiciones dignas, pretenden retornar, pero las pocas casas construidas por el Gobierno, hace cuatro años no cuentan con servicios públicos.

En marzo de 2016, se cumplieron 16 años del desplazamiento y el anhelado retorno aún no se cumple. Entre tanto, las mujeres siguen tejiendo, con el acompañamiento de algunos hombres que también lo hacen; con la misma 
técnica, tela sobre tela, pero con diferente contenido; ya no tejen el drama de la muerte, de las armas, de la violencia, ahora tejen la esperanza de la vida, las flores, los paisajes, las personas unidas por lo común: los sueños de paz, de reconciliación, de convivencia social en solidaridad a pesar de la adversidad experimentada. Trabajan persistentemente con sus recortes de tela y de tanto hacerlo, han percibido y se encuentran seguras de que lo hacen bien, que su trabajo es arte y lo incorporan a prendas de uso personal como blusas y faldas, pero también a artículos caseros como cojines o colchas. Han encontrado que su trabajo puede ser admirado, valorado y comercializado y que de ello pueden obtener ingresos que ayuden a su sustento diario. De tiempo atrás mantienen contactos con personas y fundaciones que apoyan la comercialización de sus productos. Igualmente se proyectan a sembrar frutales en variedades múltiples, en el terreno que compraron con los dineros que les otorgaron en noviembre de 2015, a raíz de ser declarado el trabajo unido y persistente de esta organización como excepcional y por tanto haber recibido el Premio Nacional de Paz. Las cosechas estarán destinadas a la producción de mermeladas, para que quienes las compren degusten sabores de paz. Actualmente se encuentran estableciendo contactos con empresas que pueden convertirse en demandantes de sus productos.

\section{Conclusiones}

T a experiencia investigativa desborda lo esperado; la complejidad del mundo real va más allá de los constructos mentales y por tanto contribuye a despejar la pregunta inicial y a generar nuevas preguntas alrededor de las categorías en estudio.

El encuentro con las mujeres de Mampuján, permitió evidenciar lo siguiente: Sobre los roles socioculturales. Se evidenció el encuentro con mujeres que descubren que su desarrollo personal no solo se cumple en el mundo de su hogar, es decir de la atención a su grupo familiar; mujeres que han comprendido que trabajar por objetivos que trascienden lo cotidiano, supone organizar su vida familiar de manera diferente. Forman a sus familias en nuevas ideas, en responsabilidades compartidas en comunicación abierta y democrática. Debaten y reflexionan al interior del hogar con cada uno de sus miembros sobre las arraigadas creencias respecto a tareas estrictamente femeninas en el hogar y tareas estrictamente masculinas por fuera de él. Las mujeres que tienen un compromiso mayor con la organización han logrado que sus esposos o compañeros e hijos, valoren y respeten sus actividades generalmente asociadas al cumplimiento de objetivos y procesos sociales. Han descubierto que socializar 
sus experiencias tiene un alto significado como medio y método para estimular en otras regiones y territorios el impulso a diferentes formas asociativas que tengan en mente la reivindicación de derechos.

Desde luego, varias mujeres encuentran resistencias y barreras, cuando confrontan al interior del hogar ideas arraigadas en la cultura machista, que persisten en el intento de adormecer y empobrecer a las mujeres; en estos casos, optan por llevar sobre sus hombros lo doméstico y las actividades y compromisos del colectivo de la organización, para lo cual generan diversas estrategias que les permiten contar con los tiempos para sus trabajos con el colectivo.

En muchas ocasiones han tenido que confrontar a familiares que desde posiciones autoritarias han pretendido desconocer, descalificar sus actuaciones o presionar por su desvinculación de estas tareas. En la vida de la asociación estas situaciones se analizan y fluyen las reflexiones que apuntan a apoyar a las mujeres en pro de la búsqueda de sus propias decisiones y autonomía.

Sobre la organización. A pesar de tener varios años de constituida, se percibe cierta debilidad en su estructura interna en lo relacionado con el establecimiento de funciones y responsabilidades por cargos directivos; aún no cuentan con comités de trabajo que permitan dividir las tareas y responsabilidades. Se percibe el liderazgo centrado en pocas personas, producto entre otras cosas de la inexistencia en nuestra cultura de formación que alimente y estimule la causa solidaria, como factor base para que muchas voces se expresen, muchas palabras sean escritas, muchos argumentos resuenen en los oídos de otros, muchas acciones de mujeres converjan con las acciones de otras mujeres y hombres en la búsqueda de gestión y movilización por intereses mutuos. En fin, para que las líderes no se agoten por llevar en sus hombros tanta responsabilidad.

Ellas, las mujeres que son líderes, entienden que las actividades en solitario no tienen mayor sentido y que la fuerza del colectivo, la cercanía con otras que vivencian las mismas necesidades es lo que se debe trabajar para avanzar en la construcción de cambios y transformaciones sociales. Identifican que el hecho de estar organizadas les ha permitido desarrollar procesos y acciones de resistencia ante embates de toda índole, no solo el conflicto armado también las violencias intrafamiliares. 
Sobre la participación, el empoderamiento y la equidad de género, los reconocen como búsquedas que de manera engranada contribuyen en sus avances. Si este engranaje es favorable, los liderazgos, centrados hoy en pocas mujeres, contribuirán a que día a día muchas se destaquen, se reconozcan y sean reconocidas por la comunidad como aportantes de manera diversa pero concreta y efectiva al desarrollo de sus organizaciones y por ende a la búsqueda de la restauración de sus derechos.

Tradicionalmente el poder, se ha acumulado en quienes se han otorgado plenas ventajas para mantener para sí el control y las decisiones sobre otros, influyendo en la distribución de los recursos materiales, el conocimiento y la ideología que gobierna las relaciones sociales, tanto en la vida privada como en la pública. Esta prerrogativa históricamente en la edad moderna estuvo en los hombres, pero las transformaciones sociales acumuladas inauguraron el desmoronamiento de este estereotipo anclado en el pasado. Las mujeres de Mampuján demuestran que avanzan en este terreno, la reciedumbre lograda a partir del manejo de múltiples situaciones críticas ha moldeado su mente y su cuerpo; gran parte de las decisiones, y acciones está en sus manos, en sus esfuerzos y luchas.

Lo encontrado con las mujeres de esta asociación, permite afirmar que han experimentado y experimentan en su diario vivir, procesos de transformación interna que las han impulsado a introducir cambios y ajustes en la dinámica de su mundo privado, en los procesos de interacción con sus cercanos, ganando el respaldo y el respeto por sus propias búsquedas. Además han tenido la posibilidad de esclarecer ideas y conceptos referentes a las dinámicas sociales y a las fuerzas que en una sociedad de mercado operan para hacer de unos detentadores de poder y de otros receptores de hechos y eventos que vulneran la condición humana; pero también y a pesar del dolor, sufrimiento e insania de sus victimarios, persisten en asumir la defensa de la vida, le apuestan al esclarecimiento de lo no dicho, de las verdades que aún están escondidas, creen en los procesos de justicia y reparación y han ido aún más lejos, han perdonado a sus victimarios. Es decir le apuestan de manera total y radical a la construcción de paz, a la posibilidad de soñar con lo impensable la construcción de un país diferente e incluyente. 


\section{REFERENCIAS BIBLIOGRÁFICAS}

Ayala, Germán (2007). La ética en las humanidades contemporáneas: un asunto del lenguaje y de la comunicación". Publicación digital. La Otra Tribuna. Un espacio de reflexión humanística, con énfasis en asuntos políticos y mediáticos. Disponible en http://laotratribuna1.blogspot.com. co/2007/11/la-tica-en-las-humanidades.html. Consultado en Julio 30/16.

Arias, Angélica (2008). Monografía político electoral Departamento de Bolívar 1997 a 2007. Misión de Observación Electoral- Corporación Nuevo Arco Iris. Disponible en: http://moe.org.co/home/ doc/moe_mre/CD/PDF/bolivar.pdf. Consultado en: Septiembre/16.

Barreto, Juanita (1997). “Develando algunos obstáculos para la participación de las mujeres". En: Otras palabras. Mujer, ética, política y participación. Bogotá. Publicación Grupo Mujer y Sociedad. Universidad Nacional de Colombia. Corporación Casa de la Mujer y Fundación Pro mujer. No. 2 (Enero Junio) (P. 39, 41).

Centro Nacional de Memoria Histórica (2015). Una nación desplazada: informe nacional del desplazamiento forzado en Colombia. Bogotá, CNMH-UARIV 2015.

Centro de Monitoreo de Desplazamiento Interno del Consejo Noruego para Refugiados (2015). Informe global 2015: desplazados internos por conflictos y violencia. (Mayo). Disponible en: http://www.acnur.org/t3/fileadmin/scripts/doc.php?file=t3/fileadmin/Documentos/portugues/ Publicacoes/2015/10060. Consultado en: Agosto/16.

Fernández, Lourdes (2000). Roles de género -mujeres académicas- iconflictos? Resumen de notas para el III Congreso Internacional Multidisciplinario sobre Mujer, Ciencia y Tecnología. Universidad de Panamá. Julio 2016. Disponible en: http://www.oei.es/historico/salactsi/lourdes.htm. Consultado en Agosto/16.

Grupo de Memoria Histórica (2013). iBasta Ya!. Colombia: Memorias de guerra y dignidad. Bogotá: Imprenta Nacional.

Gómez, Diana (2005). "Participación, representación y empoderamiento de las mujeres. Consideraciones desde el proceso de construcción colectiva de la política pública de mujer y géneros. En: Hacia el plan de igualdad de oportunidades. Elementos conceptuales. Serie Construcción colectiva de la política pública de mujer y géneros". Bogotá. Volumen 3. (P. 35-37).

Guzmán, Germán; Fals Borda, Orlando \& Umaña, Eduardo (1962). La violencia en Colombia. Estudio de un proceso social. Tomo I. Monografías sociológicas No. 12. Facultad de Sociología. Universidad Nacional de Colombia. Bogotá. (p. 36,37 y 292).

Ramírez, Juan Carlos \& De Aguas, Johan (2015). Escalafón de la competitividad de los departamentos de Colombia. CEPAL Colombia. Disponible en: http://www.cepal.org/sites/default/ files/document/files/escalafon_de_competitividad_2015_0.pdf. Consultado en: Septiembre/16

Ramírez, Socorro (1989). Las estrategias de sobrevivencia como una de las dimensiones del movimiento de mujeres. Disponible en: http://www.raco.cat/index.php /boletinamericanista/article/ viewFile/98560/146157. Consultado en: Junio/16. 
Srilatha, Batliwala (1997). El significado del empoderamiento de las mujeres: Nuevos conceptos desde la acción. En: Magdalena León, Poder y empoderamiento de las mujeres. T/M Editores, Santa Fe de Bogotá, 1997, pp. 187-211.

Ruiz, Juana (2013). Vivencias. Narraciones comunitarias de la historia, los aprendizajes y el desarrollo de la ruta jurídica en el marco de la Sentencia 34547 de Justicia y Paz, a partir de las experiencias de Mampuján. Auspicio Departamento de Justicia de los Estados Unidos de América. María la Baja. Bolívar. (p. 1-26).

Vargas, Alejo (1994). Participación social, planeación y desarrollo regional. Bogotá. Empresa Editorial Universidad Nacional de Colombia.

Villarreal, Norma (2016). Movimientos de mujeres y participación política en Colombia.1930-1991. Disponible en: http://www.ub.edu/SIMS/pdf/HistoriaGenero/HistoriaGenero-04.pdf. Consultado en: Junio/16. 

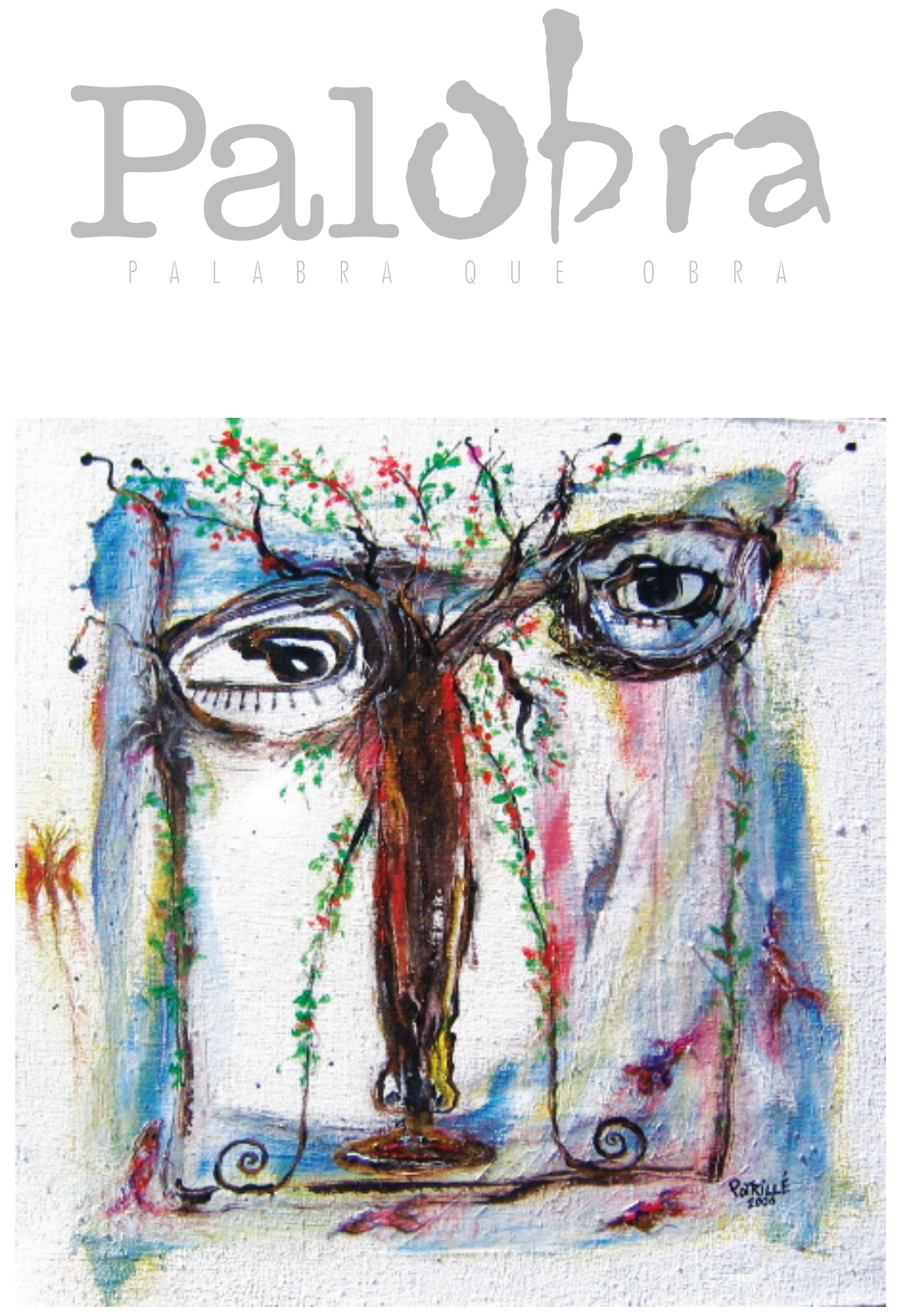

Obra pictórica de la serie "Rostros" de Eduardo Potrillé 